\title{
PROCESSO DE TERRITORIALIZAÇÃO NA INTEGRAÇÃO ENSINO-SERVIÇO-COMUNIDADE
}

UNIVALI

\author{
THE PROCESS OF TERRITORIALISATION IN THE \\ INTEGRATION BETWEEN EDUCATION, SERVICE \\ AND COMMUNITY
}

\author{
PROCESO DE TERRITORIALIZACIÓN EN LA \\ INTEGRACIÓN ENSEÑANZA-SERVICIO-COMUNIDAD
}

\author{
Marcos Aurélio MAEYAMA1 \\ Júlia Boron VIVAN \\ Antônio Renor ZAPPELINI NETTO \\ Bruna Luiza SCHNORRENBERGER \\ João Pedro Berardi PASSOS \\ Daniela de Araújo ZENONI \\ Mariana Vilela VEIGA \\ Viviane dos Santos CAMPOS \\ Jéssica Lüders BUENO \\ Camila Bentes COSTA
}

Licença CC BY:

Artigo distribuído sob os termos Creative

Commons, permite uso e distribuição irrestrita em qualquer meio desde que $o$ autor credite a fonte original.
RESUMO: A criação do Sistema Único de Saúde traz consigo o ordenamento para reorientação dos serviços de saúde a partir do conceito ampliado de saúde. Nesse sentido, o conhecimento dos determinantes sociais de uma população é fundamental para o processo de planejamento das ações para abordagem integral do processo saúdedoença. O objetivo deste trabalho foi relatar a experiência da integração ensino-serviçocomunidade no processo de territorialização de uma área de abrangência de uma equipe de Saúde da Família. A coleta de dados foi realizada a partir da saída a campo, entrevista com informantes-chaves e sistemas de informação. Os resultados demonstraram que a população do território tem acesso a alguns determinantes sociais e privação de outros, que potencialmente podem ser determinantes para a situação da saúde atual e futura, devendo ser objeto de discussão e ação da equipe de saúde local no planejamento de ações.

PALAVRAS-CHAVE: Determinantes sociais da Saúde. Diagnóstico Comunitário. Atenção Básica à Saúde. Sistema Único de Saúde.

ABSTRACT: The creation of the Unified Health System (SUS) involved the planning for reorientation of the health services, based on an enhanced concept of health. Thus, an awareness of the social determinants of a population is essential for planning actions for an integral approach to the health-disease process. This work reports on an experience of integrating education, service 1 Doutor em Saúde Coletiva pela Universidade Federal de Santa Catarina - UFSC. Mestre em Saúde e Gestão do Trabalho pela Universidade do Vale do Itajaí - UNIVALI. Graduado em Odontologia pela Organização Santamarense de Educação e Cultura - OSEC. Professor Universitário. | E-mail: marcos.aurelio@univali.br. 
and community in the process of territorialization of an area covered by a Family health team. Data were collected through a field trip, interviews with key informants, and information systems. The results showed that the population of the territory has access to some social determinants but is deprived of others that could potentially be determinants for the current and future health scenarios, and should be a subject of debate and action by the local health team in the planning of actions.

KEY WORDS: Social Determinants of Health. Community Health Services. Primary Health Care. Unified Health System.

RESUMEN: La creación del Sistema Único de Salud trae consigo el orden para reorientación de los servicios de salud a partir del concepto ampliado de salud. En este sentido, el conocimiento de los determinantes sociales de una población es fundamental para el proceso de planificación de las acciones para el abordaje integral del proceso salud-enfermedad. El objetivo de este trabajo fue relatar la experiencia de la integración enseñanza-servicio-comunidad en el proceso de territorialización de un área de alcance de un equipo de Salud de Familia. La recolección de datos fue realizada a partir de la salida de campo, entrevista con informantes-claves y sistemas de información. Los resultados demostraron que la población del territorio tiene acceso a algunos determinantes sociales y privación de otros, que potencialmente pueden ser determinantes para la situación de la salud actual y futura, debiendo ser objeto de discusión y acción del equipo de salud local en la planificación de acciones.

PALABRAS-CLAVE: Determinantes sociales de la Salud. Diagnóstico Comunitario. Atención Básica a la Salud. Sistema Único de Salud.

\section{INTRODUÇÃO}

A saúde pública no Brasil, especialmente no período do governo militar, privilegiou a construção de um modelo de atenção, cuja característica se baseava na explicação biológica do processo saúdeadoecimento, voltado para a cura de doenças de forma concreta e objetiva, com influência da racionalidade positivista e do pensamento neoliberal de consumo de bens e serviços (PAGLIOSA; DA ROS, 2008).

Como ocorrido em outros países, o modelo biomédico se mostrou insuficiente para responder às necessidades de saúde da população; e ainda no plano coletivo, foi incapaz de melhorar os indicadores de saúde (CUTOLO, 2001).

A criação do Sistema Único de Saúde (SUS) em 1988 traz consigo a determinação de reorganização do sistema a partir do conceito ampliado de saúde, incorporando os aspectos econômicos, sociais, culturais e bioecológicos da saúde. Portanto, prevê uma abordagem integral do processo saúdedoença, que não se resume à prestação de serviços assistenciais, e se estende às ações de prevenção e de promoção da saúde (VASCONCELOS; PASCHE, 2006).

Esse entendimento de integralidade do processo saúde-doença parte da premissa de determinação social, que considera saúde e adoecimento como resultado da organização política e econômica da sociedade, com acesso ou privação aos determinantes sociais, como educação, trabalho, renda, alimentação moradia, entre outros (TAMBELLINI; SCHÜTZ, 2009). Nesse sentido, diversos estudos têm demonstrado a relação entre os determinantes sociais com o estado de saúde (CNDSS, 2008). 
O modelo escolhido pelo SUS para reorganização do sistema de saúde foi o de Rede de Atenção coordenada pela Atenção Básica em Saúde, tendo a integralidade como eixo.

A Atenção Básica se caracteriza por um conjunto de ações ofertadas no âmbito individual e coletivo - incluindo a promoção da saúde, a prevenção de doenças, a recuperação e a reabilitação -, com o objetivo de ofertar atenção integral para uma população adscrita de um determinado território, que impacte na situação de saúde e nos determinantes sociais (BRASIL, 2012).

Para tanto, cada equipe de Atenção Básica deve conhecer seu território, com seus problemas, fragilidades e potencialidades para planejar e ofertar ações que atendam às necessidades específicas desta comunidade.

A territorialização representa importante instrumento de organização dos processos de trabalho e das práticas de saúde, uma vez que as ações são implementadas sobre uma base territorial previamente definida (MONKEN; BARCELLOS, 2005).

Assim, a territorialização pode ser entendida como o processo de apropriação do território pela equipe de saúde, que representa o conhecimento da realidade sociossanitária da população adscrita, propiciando a realização da microgestão e do planejamento local a partir das necessidades da comunidade (OLIVEIRA, 2006).

O território deve ser entendido como espaço de permanente construção, desconstrução e reconstrução, que além do território-geográfico, é também um território econômico, sanitário, político, cultural e epidemiológico, assim compreendido como território-processo (MENDES et al., 1993).

Conforme define a Lei 8080/90, a saúde é dependente das condições de alimentação, moradia, saneamento básico, meio ambiente, trabalho, renda, educação, transporte, lazer, segurança, além de outros bens essenciais (BRASIL, 1990), que, em última análise, representa as condições de vida das pessoas. Portanto, o conhecimento da realidade epidemiológica das pessoas, além dos dados clínicos, deve também considerar aspectos que dizem respeito às condições de vida destas pessoas, o qual, por sua vez, propicia a realização das ações de prevenção e promoção da saúde.

Em termos oficiais, a territorialização começa a ser citada apenas a partir do lançamento da Política Nacional de Atenção Básica de 2006, e posteriormente reproduzida nas duas republicações da política em 2011 e 2017 (BRASIL, 2006a; BRASIL, 2012; BRASIL 2017). Porém, desde o início do Programa Saúde da Família em 1994, já havia a definição no processo de trabalho das equipes, a realização do diagnóstico comunitário e do planejamento local, que em outras palavras se resume ao processo de territorialização (BRASIL, 1997).

Ainda que as publicações das políticas de Atenção Básica ao longo do caminho acumulem avanços e retrocessos em diversos aspectos, o processo de territorialização sempre esteve presente como atribuição de todos os membros da equipe, demonstrando a importância deste processo na construção de um modelo de atenção integral.

Nesse contexto, se a formação em saúde deve estar articulada com as demandas do sistema nacional de saúde vigente, a integração ensino-serviço-comunidade deve incluir atividades de conhecimento do território, para uma lógica de formação baseada na integralidade das ações (BRASIL, 2014), pois é a partir da reorientação de conteúdos e de vivências significativas durante o período de formação é que novas práticas de saúde poderão ser transformadoras para mudança do modelo de atenção e melhoria dos indicadores de saúde da população. 
Respondendo a essas demandas de formação em saúde, o Curso de Medicina, na disciplina de Saúde Coletiva, articulada ao PET GraduaSUS, realizou junto a uma equipe de Atenção Básica o processo de territorialização, com o objetivo de conhecer a realidade da comunidade em que realizariam o estágio nos períodos subsequentes do curso.

\section{METODOLOGIA}

Trata-se de um relato de experiência, realizado pelos alunos do $2^{\circ}$ período do Curso de Medicina, na disciplina de Saúde Coletiva, vinculada ao PET GraduaSUS, junto a uma equipe de Atenção Básica, localizada num município do Vale do Itajaí - SC.

O relato de experiência é uma modalidade de registro documental do percurso acadêmico desenvolvido em estágios ou projetos de extensão, e sua publicização se justifica a partir de situações relevantes ocorridas nesse processo, que podem contribuir para o desenvolvimento da área em questão (RIO DE JANEIRO, 2018).

No início do estágio acadêmico, a partir da integração com a equipe de saúde, foi discutida a necessidade de conhecimento dos alunos referente ao território de abrangência sob responsabilidade da equipe.

Como objetivos da territorialização, foram destacadas a importância do conhecimento das condições de vida da comunidade, as iniquidades existentes no território, bem como as potencialidades e as fragilidades locais, para finalmente compor a realização do diagnóstico comunitário (UFPB, 2011 ).

A obtenção das informações foi realizada por meio da saída de campo, entrevista com informanteschaves e busca de dados no sistema de informação (OLIVEIRA, 2006).

Em resumo, a territorialização ocorreu conforme Figura 1.

\section{FigURA 1: Processo de Territorialização.}

Fonte: Elaborada pelos autores.

Na saída de campo, foram observadas as moradias, os terrenos baldios, o comércio existente, os equipamentos sociais, as condições de calçamento, o fornecimento de água e o esgoto, a energia elétrica, entre outros.

As entrevistas foram realizadas com moradores mais antigos da comunidade, lideranças do bairro e funcionários da Unidade Básica de Saúde (UBS), buscando identificar as potencialidades e as fragilidades da comunidade a partir dos determinantes sociais e do conceito ampliado de saúde.

Quanto ao sistema de informações, foram coletados dados do GEMUS/E-SUS, que consolida informações sobre o cadastro individual e familiar das pessoas da área adscrita, com dados referentes às condições de moradia, doenças autorreferidas, doenças ou situações de saúde de acompanhamento longitudinal e ainda dados de produção da equipe quanto aos atendimentos realizados na UBS e território.

Ao longo do processo e a partir da sistematização das informações, os alunos foram convidados a refletir sobre as condições de vida da comunidade, bem como buscar referencial teórico que relacionasse a interferência dos determinantes sociais na condição de saúde da população. 


\section{RESULTADOS}

Após a triangulação de dados, o retrato da comunidade estudada apresentou características diversas, conforme Figura 2.

\section{FIGURA 2: Diagnóstico Comunitário.}

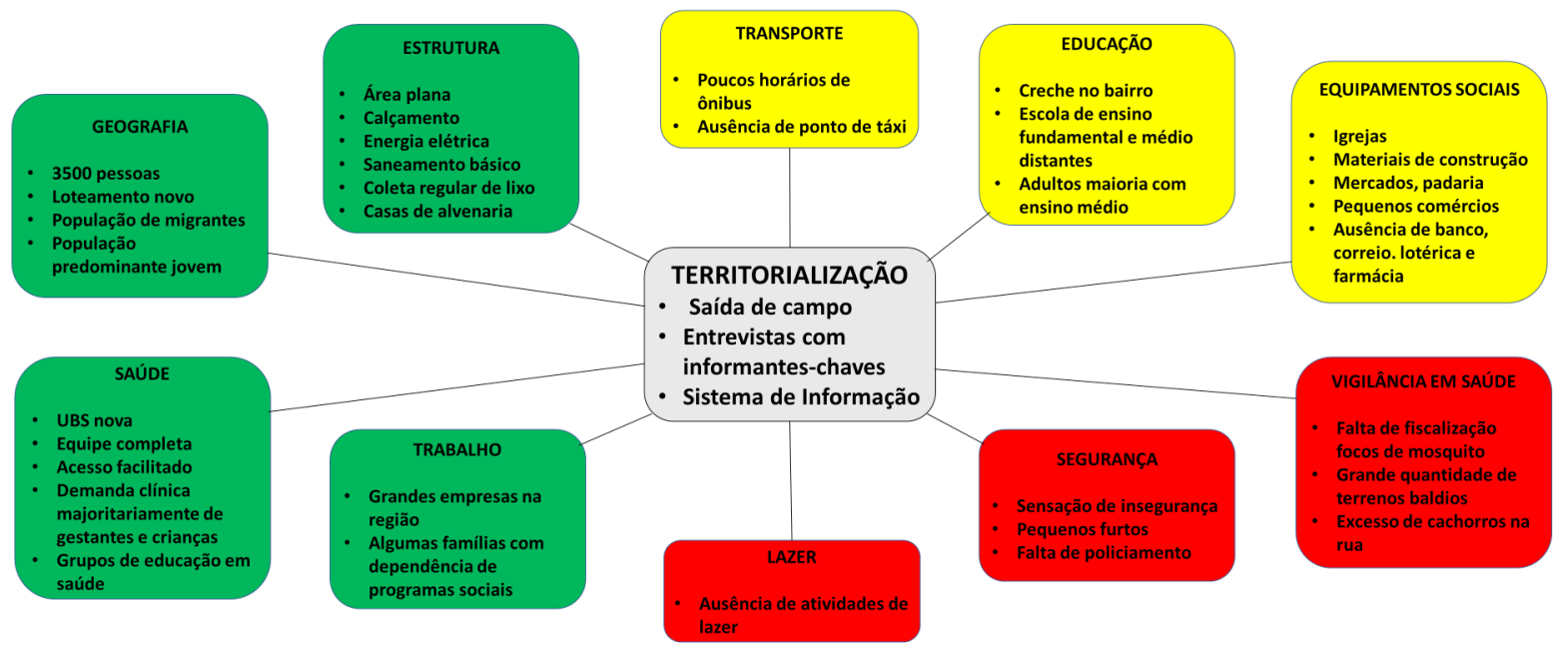

FONTE: Elaborada pelos autores.

O loteamento em que foi realizada a territorialização é recente (10 anos), sendo que a maioria da população é formada por migrantes de outros municípios e de outros Estados. Os Estados mais prevalentes de origem são Pernambuco e São Paulo.

Quanto aos aspectos geográficos, houve o reconhecimento do território, apresentando área plana, sem rios, composto basicamente por seis ruas paralelas e quatro transversais, todas com calçamento. Região com expressivo número de habitações (considerando o curto período de existência do bairro), sendo a maioria casas de construção própria em alvenaria, algumas inacabadas, diversas igrejas (aproximadamente oito) e quantidade considerável de terrenos baldios (não contabilizando as áreas verdes), pois ainda existem terrenos disponíveis do loteamento inicial.

Não há ocorrência de esgoto ao ar livre, existe fornecimento de saneamento básico, água encanada e luz elétrica em todas as residências, no entanto existem relatos de problemas quanto à qualidade da água e à queda de energia elétrica. A comunidade possui coleta urbana de lixo orgânico, que acontece três vezes por semana, além da coleta semanal de lixo reciclável, porém ainda ocorre queimação de lixo nas residências. Segundo informações da ex-presidente da associação de moradores do bairro, essas conquistas de infraestrutura foram fruto de reivindicações da comunidade junto ao poder público.

Por outro lado, ainda não há serviços como correios, lotéricas e agências bancárias na região, bem como serviço de atendimento de emergência e farmácias, exceto a existente na Unidade Básica de Saúde. 
A equipe da Estratégia de Saúde da Família, que realizou a integração ensino-serviço-comunidade, foi criada no final do ano de 2015 e engloba o atendimento de aproximadamente 3500 pessoas / 1000 famílias devidamente cadastradas.

A população mais prevalente do atendimento clínico/assistencial dessa equipe corresponde a gestantes e crianças, fato explicado pelo perfil da população, cuja maioria é jovem, com famílias novas (recém-casados jovens) e com filhos. O acesso à Unidade Básica de Saúde é bastante facilitado, pois a equipe, além de ser completa, conta com duas médicas residentes, ampliando a capacidade de atendimento médico, o que em geral é ponto de reclamação em muitas unidades de saúde. As doenças mais prevalentes são as da infância; há poucos hipertensos e diabéticos (uma média de 80 ao todo), especialmente por tratar-se de uma comunidade jovem. Além das atividades assistenciais, a equipe realiza atividades de educação em saúde voltadas para gestantes, pessoas com doenças crônicas e ainda existe um grupo de apoio para tabagistas. Também são realizadas visitas domiciliares para as pessoas que não conseguem se deslocar até a unidade de saúde.

Uma das fragilidades apontadas pelos entrevistados é que, mesmo diante da grande quantidade de terreno baldio, o bairro apresenta raras visitas para fiscalização de focos de mosquitos, sendo aproximadamente uma vez por ano e mais prevalente no comércio. E ainda existe grande quantidade de cachorros abandonados nas ruas. Ambos os casos potencialmente podem ser vetores para transmissão de doenças.

Há uma creche (CEI) no local, que atende as crianças da região até 5 anos de idade, bem estruturada, que proporciona uma educação adequada para as crianças desta faixa etária. A equipe de saúde realiza acompanhamento do crescimento e do desenvolvimento destas crianças na própria creche com visitas periódicas a cada três meses. Por outro lado, segundo relatos da população, há ainda a necessidade da ampliação do número de vagas, bem como de uma escola com Ensino Fundamental e Ensino Médio, já que as crianças e os adolescentes precisam se deslocar para outro bairro para estudar, sendo a escola mais próxima situada aproximadamente a $2 \mathrm{~km}$, do outro lado da rodovia.

Na população mais jovem a média de escolaridade é de nível médio (completo e incompleto), enquanto nas pessoas acima de 50 anos, em sua maioria possuem fundamental incompleto.

Quanto à oportunidade de emprego, na comunidade existem algumas empresas de pequeno porte, em sua maioria familiar, como minimercados, costureira, papelaria, lan house, barbearia, padarias, loja de material de construção, loja de roupas e bares. No entorno, existem empresas de grande porte, que não fazem parte da área de abrangência da equipe, mas que emprega a maioria da mão de obra da região, por isso a taxa de desemprego não é alarmante, segundo informação da população entrevistada.

A renda da população é bastante variada, tendo desde famílias totalmente dependentes de subsídios do governo, como famílias com renda em torno de 5 salários mínimos.

Além disso, não há serviço de táxi e os horários de ônibus são bastante limitados, o que dificulta o deslocamento da população para outros bairros do município, inclusive no acesso a outros serviços que não são oferecidos no bairro.

O território é carente quanto às áreas de lazer, havendo apenas uma academia ao ar livre, situada no pátio da Unidade de Saúde que, segundo alguns moradores, apresenta-se de forma precária, com equipamentos enferrujados, não sendo muito utilizado por esse motivo. A exceção fica por conta de um programa voltado para a promoção da atividade física, que já funciona nesta academia 
com presença de profissional de educação física e conta com a participação de alguns membros da comunidade. Não existem praças ou qualquer outro tipo de espaço coletivo destinado à população.

Um ponto muito relevante na pesquisa foi o relato quanto à falta de segurança, na qual muitas pessoas referem não se sentir seguras no território e relatam casos de assaltos e roubos nas moradias. Há pouco policiamento no bairro, sendo que a presença em geral só ocorre quando requisitado pela população por alguma ocorrência. Por esse motivo, existem casas com cerca elétrica e muitos moradores relatam possuir cachorro na residência como forma de inibir a criminalidade.

\section{DISCUSSÃO}

\section{Segurança}

A segurança apresenta importante relevância quando se discute a questão da saúde. Segundo dados de 2013 do Sistema de Informação sobre Mortalidade (SIM), a morte por homicídio representava a quinta causa de morte mais prevalente no Brasil. Se se considerar apenas a população jovem entre 15 e 29 anos, a violência corresponde à principal causa de mortalidade (BRASIL, 2013).

Para se entender a dimensão do problema, no Brasil, em três semanas são assassinadas mais pessoas do que o total de mortos em ataques terroristas no mundo nos cinco primeiros meses do ano de 2017 (CERQUEIRA et al., 2017). Ainda que as notícias sobre a violência alcancem os veículos de mídia, o destaque maior é para os atentados terroristas, e a discussão sobre a segurança pública no Brasil pouco é veiculada pela mídia, autoridades e pela própria população.

Dados do SIM demonstram que a taxa de homicídio no Brasil teve um aumento de 30,1\% no período entre 2005 e 2015 e só no último período, entre 2014 e 2015, o aumento foi de 4,3\% (CERQUEIRA et al., 2017).

Segundo dados do Atlas da Violência de 2017 (estudo realizado pelo Instituto de Pesquisa Econômica Aplicada - Ipea em parceria com o Fórum Brasileiro de Segurança Pública - FBSP), Itajaí apresenta taxa de 20,9 mortes por homicídio a cada 100.000 habitantes, sendo que a Organização Mundial da Saúde considera como área endêmica acima de 10 homicídios por 100.000 habitantes, representando uma das cidades mais violentas do Estado (CERQUEIRA et al., 2017).

Isso justifica a preocupação crescente com a segurança relatada pelos entrevistados, que já vivenciaram direta ou indiretamente a violência dentro da comunidade.

O cenário supramencionado representa o descompromisso do Estado brasileiro com a segurança pública, sem planejamento e execução de ações que garantam minimamente os direitos de cidadania (CERQUEIRA et al., 2017).

A violência é exacerbada em períodos de crise econômica, especialmente em Estados que não garantem proteção social, privando as pessoas do mínimo necessário para sua subsistência (OMS, 2011), o que é motivo de preocupação no cenário brasileiro com o desmonte das políticas sociais do atual governo. Isto faz com que a oportunidade de entrar no mundo do crime aumente, pelo desemprego, pela falta de oportunidades e pela baixa perspectiva de futuro (CERQUEIRA et al., 2017).

Por outro lado, o inverso também é verdadeiro, os sistemas de proteção social e o crescimento econômico redistributivo também desincentivam a criminalidade e a violência. Não se combate criminalidade apenas com segurança pública, ainda que esta seja extremamente necessária. 


\section{Transporte}

Ainda que o transporte possa não ter relação aparente com a saúde, a sua limitação pode privar o cidadão do acesso a bens essenciais, como educação, trabalho, lazer, relações sociais, e, inclusive, aos serviços de saúde (GUIMARÃES, 2012), influenciando desta forma indiretamente a condição de saúde.

As áreas de ocupação do solo sem fundamentação legal ou a ocupação não planejada podem causar prejuízo às pessoas quanto à mobilidade e, em geral, podem levar a uma demanda tardia para o Poder Público de infraestrutura de serviços, como o transporte (BRASIL, 2015). Em geral, esses locais pertencem à periferia dos centros urbanos, cujo valor da terra é mais acessível e a ocupação é feita em geral por pessoas sem qualificação e famílias de baixa renda (BRASIL, 2015). Mesmo em ocupações autorizadas e regularizadas, especialmente na periferia das cidades, o planejamento urbano e de mobilidade nem sempre é realizado e a infraestrutura e os serviços essenciais acabam sendo demandados a posteriori (BRASIL, 2015).

A Constituição Federal considera a prestação de serviço de transporte urbano coletivo como atribuição do município, porém ela também permite concessões ou permissões à iniciativa privada para a prestação deste serviço, desde que garantidas a eficácia e a eficiência dos serviços (BRASIL, 2015).

Todavia, se por um lado os recursos públicos são cada vez mais escassos, por outro a iniciativa privada é mediada pelos interesses econômicos, o que acaba prejudicando o atendimento das necessidades por transporte coletivo da população (BRASIL, 2015).

Isso tem levado a um grande descontentamento dos usuários de transporte coletivo, confirmado pela pesquisa realizada pelo Instituto de Pesquisa Econômica Aplicada (Ipea) em 2012, em que mais de $60 \%$ dos entrevistados consideraram como péssimos ou ruins o transporte coletivo (BRASIL, 2015). As reclamações mais frequentes referem-se à baixa disponibilidade de viagens e horários, superlotação e falta higiene e segurança (BRASIL, 2015).

Essas afirmativas vão ao encontro das informações coletadas junto à população local, que reclama da pouca disponibilidade de horários, especialmente considerando a distância do bairro para o centro da cidade (aproximadamente $10 \mathrm{~km}$ ), ou para os principais serviços de urgência e emergência (aproximadamente $11 \mathrm{~km}$ do Hospital Regional e $5 \mathrm{~km}$ da Unidade de Pronto Atendimento).

Por este motivo o planejamento de estradas, os sistemas de transporte e a habitação devem considerar o impacto na saúde das pessoas, favorecendo o acesso a bens e serviços essenciais. Além disso, o planejamento urbano deve considerar outras formas de transporte que protegem a degradação ambiental, como o uso de bicicleta e caminhada, de forma segura e agradável, fortalecendo a saúde coletiva e individual (OMS, 2011).

Na comunidade em questão não existe ciclovia no bairro, nem na rodovia que dá acesso a ela, dificultando a utilização deste meio de transporte e ainda colocando em risco as pessoas que fazem uso da bicicleta pela falta de condições e segurança.

\section{Educação}

Existem diversos estudos que relacionam a situação de saúde com a escolaridade, desde a ocorrência de doenças crônicas (ISHITANI et al., 2006; BARROS et al., 2006), a influência na mortalidade infantil (IBGE, 2005) até a expectativa de vida (MESSIAS, 2003), entre outros. 
Essa relação é explicada por conta da influência da baixa escolaridade na percepção dos problemas de saúde, na busca e no acesso aos serviços de saúde, na capacidade de entendimento das informações sobre saúde, na possibilidade de adoção de estilos de vida saudáveis e, consequentemente, na adesão ao tratamento (MESSIAS, 2003).

A baixa escolaridade pode também dificultar a inserção no mercado de trabalho em funções que exijam conhecimentos específicos (AURIGLIETTI; LÖRH, 2014). Em consequência pode haver comprometimento da renda. Da mesma forma que a escolaridade, a renda, ou melhor, a privação dela, está relacionada com uma pior condição de saúde (MESSIAS, 2003).

O panorama nacional de evasão escolar no Brasil é preocupante. Dados do censo de 2010 demonstram que existem mais de 3,8 milhões de crianças e adolescentes, desde os 4 até os 17 anos, fora da escola (IBGE, 2010). Diversos estudos têm buscado explicar esse problema, e as principais causas estão relacionadas a distância da escola, falta de transporte escolar, não presença de adulto que leve à criança até a escola, falta de interesse, doenças/dificuldades dos alunos, e ainda questões relacionadas ao preconceito e à pobreza (BRASIL, 2007).

Em levantamento realizado pela Unicef, a Região Sul, juntamente com a Região Norte, apresenta as maiores taxas de evasão escolar na faixa dos 15 a 17 anos, ambas com 18,7\% (UNICEF, 2013).

Esses dados da Região Sul, corroborados pelas informações dos moradores quanto à distância da escola, falta de vagas e dificuldade de transporte, são motivo de preocupação e alerta para o poder público local, pois eles podem favorecer a evasão escolar dos membros da comunidade.

É importante lembrar que, além do acesso, as condições de infraestrutura e os recursos humanos também são importantes para a garantia do aprendizado. Porém, ainda que apenas o simples acesso à educação não garanta oportunidades, o redimensionamento das redes escolares e o transporte escolar adequados são o ponto de partida para iniciar o processo (UNICEF, 2013).

\section{Habitação}

A habitação sob o ponto de vista sanitário tem importância quanto ao material de construção, acesso à eletricidade, condições de fornecimento de água, tratamento de esgoto e coleta de lixo (MAGALHÃES et al., 2013). Inclusive, a qualidade na prestação destes serviços apresenta, em longo prazo, melhores resultados sanitários do que as ações provenientes de intervenções médicas (SOARES et al., 2002).

Além disso, na moradia, as condições relacionadas ao espaço, ventilação, insolação, conforto térmico e acústico, local para lazer, proteção quanto à inundação, segurança, privacidade, vida familiar e comunitária, execução das atividades domésticas e satisfação, podem interferir positivamente ou negativamente na saúde das pessoas (PASTERNAK, 2016).

Os dados do sistema de informação sobre as condições sanitárias dos domicílios e o próprio passeio ambiental demonstraram que a condição das moradias do bairro é bastante favorável, com edificações recentes e acesso às condições de saneamento básico e energia elétrica, inclusive com calçamento em todas as ruas.

No entorno, além das condições ambientais, o acesso a outros equipamentos sociais da vida cotidiana também é importante. A presença no próprio bairro de supermercados, farmácia, rede bancária, padarias, correio, feiras, comércio em geral, instituições religiosas e outros é outro elemento que 
facilita o fluxo das pessoas na vida cotidiana, otimizando tempo e recursos. Nesse sentido, o bairro ainda é desprovido de equipamentos sociais importantes, como farmácias, agências bancárias e correio, que aliados à limitação de transporte coletivo, dificulta o cotidiano da população local.

Por esse motivo, o desenho e o planejamento das habitações, tanto sob o ponto de vista estrutural quanto da oferta de serviços essenciais, devem considerar o bem-estar e a saúde das pessoas, especialmente das populações e das comunidades carentes, que em geral encontram-se mais vulneráveis em relação a outros determinantes sociais (OMS, 2011).

\section{Lazer}

Por lazer, ainda que se tenha uma dimensão subjetiva de seu sentido, pode-se considerar brincadeiras, festas, jogos, passeio, viagem, prática de esportes, atividades de arte e cultura, (pintura, escultura, literatura, dança, música, cinema), o próprio ócio e descanso, entre tantas outras possibilidades (GOMES, 2004).

A subjetividade encontra-se no fato de cada qual ter uma preferência por atividades de lazer ou experiências, que sejam agradáveis e adequadas para uso do tempo livre (BATISTA et al., 2012).

Nesse sentido, as atividades de lazer, pela possibilidade de promoção da automotivação, bem como pelo fato de proporcionarem satisfação pessoal e social, contribuem para a melhoria da qualidade de vida (GÁSPARI; SCHWARTZ, 2001).

Além disso, as atividades de lazer, em especial as relacionadas com atividade física, podem proporcionar benefícios biológicos, relacionados ao metabolismo e ao condicionamento físico. Além disso, o lazer interfere em outros determinantes sociais, como acesso à informação e à cultura, à sociabilidade, podendo atuar como agente de promoção da saúde (BATISTA et al., 2012). Por outro lado, a privação ao lazer também pode interferir negativamente na saúde das pessoas.

Um dos aspectos negativos elencados pelos moradores é que o bairro é desprovido de atividades de lazer e, mais uma vez, a dificuldade de transporte coletivo limita o acesso a outros locais para o lazer. Ainda que o conceito de lazer seja bastante amplo e subjetivo, a comunidade também pode se organizar para alternativas locais de lazer, o que não exime o poder público de ser o facilitador deste processo.

\section{Trabalho}

Diversos estudos já demonstraram que as oportunidades de trabalho e o emprego estável, independente da classe social, estão relacionados com melhor condição de saúde (OMS, 2011). Um estudo realizado nos Estados Unidos relacionou a satisfação no trabalho como um dos mais importantes aspectos para a longevidade das pessoas.

Por outro lado, estudos realizados no Brasil demonstram que o desemprego, o trabalho informal e a exclusão do mercado de trabalho estão associados a uma pior condição de saúde, independentemente das características de escolaridade, renda e região de residência (GIATTI; BARRETO, 2006).

Além disso, é inegável que o acesso ao trabalho é determinante para a renda das famílias que, por sua vez, influencia em tantos outros determinantes sociais, como moradia, alimentação, segurança, educação, entre outros. 
Se por um lado o acesso ao emprego é uma necessidade, por outro as condições de trabalho também podem ser geradoras de doenças e má condição de saúde. O desenvolvimento econômico e a transição de uma economia agrária para a industrial, ocorridos no Brasil no final do século XX, também trouxeram consigo consequências sociais com o crescimento do setor informal, baixos salários, insegurança no emprego, trabalho infantil e o próprio desemprego (CNDSS, 2008).

Aliado a isso, a organização do trabalho (ou a falta dela) também tem determinado uma maior exposição aos perigos químicos e físicos, realização de tarefas repetitivas, uso excessivo de força, posturas inadequadas, exposição ao stress e fatores psicossociais, que acabam gerando uma série de problemas de saúde (GÓMEZ; LACAZ, 2005).

Na contramão do cenário nacional, os moradores locais relatam que a taxa de desemprego é pequena pela grande oferta de empregos alavancados pela quantidade de empresas no entorno. Além disso, os dados dos serviços de saúde demonstram que não existe grande demanda por doenças ocupacionais, fato que talvez possa ser explicado por se tratar de uma população majoritariamente jovem, ainda sem as consequências geradas pela exploração do trabalho.

\section{Serviços de saúde}

Diversos estudos têm demonstrado a importância da implantação da Estratégia Saúde da Família para a população brasileira. A presença da Atenção Básica à Saúde no próprio território implica uma melhoria dos indicadores de saúde.

Uma pesquisa realizada no Brasil demonstrou que a implantação da Atenção Básica no período entre 1998 e 2004 esteve associada à melhoria dos indicadores de saúde de forma geral (BRASIL, 2006b). Um dos estudos que comprovam essa afirmativa foi realizado por Aquino et al. apud Mendes (2012), no período entre 1996 e 2004, em 721 municípios que estruturaram a Atenção Básica, os quais tiveram uma diminuição da mortalidade infantil de 26,6 para 16,1 mortes por cada mil nascidos vivos.

Outra pesquisa realizada com dados secundários do estado de Minas Gerais demonstrou que eventos de saúde sensíveis à Atenção Básica tiveram reduções significativas no período entre 2007 e 2010, que coincide com o período em que a Atenção Básica teve prioridade nas políticas estaduais, com grande diminuição de internação hospitalar por desidratação e pneumonia, diminuição da taxa de baixo peso ao nascer e óbito por infecção respiratória aguda em crianças menores de um ano (JUNQUEIRA, 2011), o que implica ainda a redução de custos financeiros e sociais ocasionados por esses agravos.

Estudos internacionais demonstram as mesmas evidências das vantagens da Atenção Primária à Saúde (APS) em relação a outras formas de organização. Mendes (2012) realizou uma revisão de literatura de estudos de diversos países e concluiu que os sistemas de saúde com forte orientação para a APS são mais adequados às necessidades de saúde da população; são mais efetivos para enfrentamento das condições crônicas, com desempenho significativo nos níveis de saúde; são mais eficientes porque apresentam menores custos e reduzem procedimentos mais caros; são mais equitativos porque discriminam positivamente grupos e regiões mais pobres e diminuem o gasto do bolso das pessoas e famílias; e ainda apresentam melhores indicadores por darem ênfase às ações de promoção da saúde e prevenção de doenças (MENDES, 2012). 
Ainda que o bairro seja de ocupação bastante recente, ele já conta com uma Unidade Básica de Saúde, com estrutura física e humana bastante adequada, o que possivelmente já interfere positivamente nos indicadores de saúde da população local, e por esse motivo foi um dos pontos destacados pela comunidade como favoráveis no bairro.

O ponto negativo quanto à saúde fica por conta do controle de vetores, em que os profissionais alegam a existência de 25 focos de Aedes Aegypti, mas que a vigilância em saúde do município, que possui Agentes de Combate a Endemias, raras vezes faz visitas ao bairro, que conta com grande quantidade de terrenos baldios, o que facilita sua proliferação.

A vigilância em saúde, em tese, deve se articular com as equipes de Atenção Básica para as ações de vigilância no território (BRASIL, 2010), porém na prática essa integração pouco acontece na maioria dos municípios brasileiros. Ocorre que as ações acabam sendo planejadas no nível central e no caso do controle de vetores, essa ação acaba sendo realizada exclusivamente pelos Agentes de Combate às Endemias, sem integração com a equipe de Atenção Básica. Porém, com um baixo quantitativo de Agentes de Combate às Endemias, a cobertura em todo o município acaba não ocorrendo de forma efetiva, propiciando o aparecimento de vetores, principalmente de mosquitos, entre eles, o Aedes Aegypti, que pode ser transmissor de Dengue, Zika, Chikungunya, como relatado pelos moradores.

\section{CONSIDERAÇÕES FINAIS}

Diversos estudos têm apontado que as iniquidades em saúde (além de sistemáticas e relevantes são também evitáveis, injustas e desnecessárias) são fruto das desigualdades de acesso aos determinantes sociais. Porém, mesmo diante das evidências, pouco se tem realizado para modificação do contexto social e consequentemente do setor saúde.

Ainda que a modificação dos determinantes sociais se situem na esfera macropolítica de decisão, são possíveis diversas ações no nível micropolítico, com organização comunitária e mobilização social. Entretanto, a tomada de decisão só ocorre com informações e evidências que demonstrem as desigualdades e as suas consequências para a situação de saúde.

O reconhecimento inicial do território demonstrou que as condições de vida da população do bairro em questão são bastante razoáveis, com destaque para as condições de moradia, saneamento básico, renda, trabalho e acesso ao serviço de saúde local.

As limitações ficam por conta do acesso ao lazer e à segurança, e também de forma relativa o acesso à educação no próprio bairro, os quais podem, ao longo do tempo, interferir negativamente na saúde da comunidade, e devem ser ponto de pauta do poder público e da própria equipe de saúde. Além disso, a falta de equipamentos sociais no próprio bairro é ainda acentuada pela baixa oferta de transporte coletivo, e também deve ser item de discussão quanto à melhoria para a comunidade local.

Esta apropriação do território permite que a equipe de saúde relacione a ocorrência de determinados problemas com os determinantes sociais e, desta forma, realize, além das ações de 
assistência, atividades de prevenção e promoção da saúde, que propiciam atenção integral e consequente melhoria das condições de vida e saúde da população (BRASIL, 2012).

A realização de atividades, como a territorialização na integração ensino-serviço-comunidade, é de extrema importância para a transformação da realidade sanitária e social de um território, mas também carrega consigo a responsabilidade de gerar processos de reflexão e ação crítica dos atores sociais, contribuindo assim para a construção de uma sociedade mais justa e igualitária, podendo assim ser considerada um importante recurso de tecnologia social.

\section{REFERÊNCIAS}

AURIGLIETTI, R. C. R.; LÖHR, S. S. Evasão e abandono escolar: causas, consequências e alternativas - o combate à evasão escolar sob a perspectiva dos alunos. In: PARANÁ (Estado). Secretaria de Estado da Educação. Os desafios da escola pública paranaense na perspectiva do professor. Cadernos PDE, v.1, p.1-21, 2014.

BARROS, M. B. A.; CÉSAR, C. L. G., CARANDINA L.; TORRE, G. D. Desigualdades sociais na prevalência de doenças crônicas no Brasil - PNAD 2003. Ciência e Saúde Coletiva, Rio de Janeiro, v.11, n.4, p.911-926, 2006.

BATISTA, J. C.; RIBEIRO, O. C. F.; NUNES JUNIOR, P. C. Lazer e Promoção de Saúde. Licere, Belo Horizonte, v.15, n.2, p.1-16, 2012.

BRASIL. Ministério da Saúde. Lei no . 8.080, de 19 de setembro de 1990. 1990. Disponível em: $<$ http://www.planalto.gov.br/ccivil_03/leis/L8080.htm>. Acesso em: set 2018.

BRASIL. Ministério da Saúde. Secretaria de Atenção à Saúde. Departamento de Atenção Básica. Política Nacional de Atenção Básica. Brasília: Ministério da Saúde, 2006a.

BRASIL. Ministério da Saúde. Saúde da família no Brasil: uma análise de indicadores selecionados, 1998-2004. 2006b. Disponível em: < http://bvsms.saude.gov.br/bvs/publicacoes/ cd10_15a.pdf>. Acesso em: set 2018.

BRASIL. Ministério da Saúde. Diretrizes Nacionais da Vigilância em Saúde. 2010. Disponível em: < http://livroaberto.ibict.br/bitstream/1/901/1/diretrizes_nacionais_vigilancia_saude.pdf $>$. Acesso em: set 2018.

BRASIL. Ministério da Saúde. Política Nacional de Atenção Básica. 2012. Disponível em: < http://189.28.128.100/dab/docs/publicacoes/geral/pnab.pdf>. Acesso em: set 2018.

BRASIL. Ministério da Educação. Diretrizes Curriculares Nacionais do Curso de Graduação em Medicina. 2014. Disponível em: < http://portal.mec.gov.br/cne/arquivos/pdf/Med.pdf> . Acesso em: set 2018.

BRASIL. Câmara dos Deputados. O desafio da mobilidade urbana. 2015. Disponível em: < http://bd.camara.gov.br/bd/handle/bdcamara/25220>. Acesso em: set 2018.

BRASIL. Instituto Nacional de Estudos e Pesquisas Anísio Teixeira. Sinopse Estatística da 
Educação Básica 2007. 2007. Disponível em: <http://www.inep.gov.br/>. Acesso em: set 2018. BRASIL. Ministério da Saúde. Portaria n. 2.436, de 21 de setembro de 2017. 2017. Disponível em: < http://bvsms.saude.gov.br/bvs/saudelegis/gm/2017/prt2436_22_09_2017.html>.Acesso em: set 2018.

BRASIL. Ministério da Saúde. Sistema de Informações sobre Mortalidade - SIM. Consolidação da base de dados de 2013. Brasília: Ministério da Saúde, 2013.

CERQUEIRA, D.; LIMA, R. S. de; BUENO, S.; VALENCIA, L. I.; HANASHIRO, O.; MACHADO, P. H. G.; LIMA, A. dos S. Atlas da Violência 2017. Rio de Janeiro: IPEA/ FBSP, 2017.

COMISSÃO NACIONAL SOBRE DETERMINANTES SOCIAIS DA SAÚDE - CNDSS. As causas sociais das iniquidades em saúde no Brasil. Rio de Janeiro: Fiocruz, 2008.

CUTOLO, L. R. A. Estilo de pensamento em educação médica: um estudo do currículo do curso de graduação em medicina da UFSC. 2001. Tese (Doutorado em Educação) -Universidade Federal de Santa Catarina, Florianópolis, 2001.

GÁSPARI, J. C.; SCHWARTZ, G. M. Adolescência, Esporte e Qualidade de Vida. Revista Motriz, Rio Claro, v.7, n.2, p.107-113, 2001.

GIATTI, L.; BARRETO, S. M. Situação do indivíduo no mercado de trabalho e iniquidade em saúde no Brasil. Revista de Saúde Pública, Rio de Janeiro, v.40, n.1, p.99-106, 2006.

GÓMEZ, C.; LACAZ, F. A. C. Saúde do trabalhador: novas-velhas questões. Ciência e Saúde Coletiva, Rio de Janeiro, v.10, n.4, p.797-807, 2005.

GOMES, C. L. (Org.) Dicionário crítico do lazer. Belo Horizonte: Autêntica, 2004.

GUIMARÃES, G. S. Comentários à lei de mobilidade urbana: Lei no 12.587/12. Belo Horizonte: Fórum, 2012.

INSTITUTO BRASILEIRO DE GEOGRAFIA E ESTATÍSTICA - IBGE. Censos Demográficos, 1991-2000 e Pesquisa Nacional por Amostra de Domicílios - PNAD. IBGE, 2005.

INSTITUTO BRASILEIRO DE GEOGRAFIA E ESTATÍSTICA - IBGE. Censo Demográfico 2010. IBGE, 2010.

ISHITANI, L. H.; FRANCO, C. G.; PERPÉTUO, I. H. O.; FRANÇA, E. Desigualdade social e mortalidade precoce por doenças cardiovasculares no Brasil. Revista de Saúde Pública, São Paulo, v.40, n.4, p.684-691, 2006.

JUNQUEIRA, M. G. Regulamentação da Emenda 29: financiamento da saúde, em busca de soluções. Belo Horizonte: COSEMS de Minas Gerais, 2011.

MAGAlHÃES, K. A.; MARTINS, T. C. P.; GOMES, A. P.; SIQUEIRA-BATISTA, R. A Habitação como Determinante Social da Saúde: percepções e condições de vida de famílias cadastradas no Programa Bolsa Família. Saúde e Sociedade, São Paulo, v.22, n.1, p.57-72, 2013. 
MENDES, E. V.; TEIXEIRA, C. F.; ARAÚJO, E. C.; CARDOSO, M. R. L. Distritos sanitários: conceitos-chave. In: MENDES, E. V. Distrito sanitário. São Paulo: Hucitec, 1993. p. 159-85.

MENDES, E. V. O cuidado das condições crônicas na atenção primária à saúde: o imperativo da consolidação da estratégia da saúde da família. Brasília: Organização Pan-Americana da Saúde, 2012.

MESSIAS, E. Income inequality, illiteracy rate, and life expectancy in Brazil. American Journal of Public Health, Washington, v.93, n.8, p.1294-1296, 2003.

MONKEN, M.; BARCELLOS, C. Vigilância em saúde e território utilizado: possibilidades teóricas e metodológicas. Cadernos de Saúde Pública, Rio de Janeiro, v.21, n.3, p.898-906, 2005.

OLIVEIRA, L. J. C. A territorialização e o planejamento local em saúde. In: CUTOLO, L. R. A. (Org.). Manual de Terapêutica: Assistência à Família. Florianópolis: Associação Catarinense de Medicina, 2006.

ORGANIZAÇÃO MUNDIAL DA SAÚDE - OMS. Diminuindo diferenças: a prática das políticas sobre determinantes sociais da saúde. Documento de discussão. Genebra, 2011.

PAGLIOSA, F. L.; DA ROS, M. A. O Relatório Flexner: para o bem e para o mal. Revista Brasileira de Educação Médica, Rio de Janeiro, v. 32, n.4, p.492-499, 2008.

PASTERNAK, S. Habitação e saúde. Estudos Avançados, São Paulo, v.30, n.86, p.51-66, 2016. RIO DE JANEIRO (Município). Secretaria Municipal de Saúde. Orientações para elaboração de relato de experiência ou estudo de caso. Disponível em: $<$ http://www.rio.rj.gov.br/dlstatic/10112/7499051/4203012/MODELOSRELATOEXPERIENCIA.ESTUDOCASO.pdf $>$. Acesso em 31 jul. 2018.

SOARES, S. R. A.; BERNARDES, R. S.; NETTO, O. M. C. Relações entre saneamento, saúde pública e meio ambiente: elementos para formulação de um modelo de planejamento em saneamento. Cadernos de Saúde Pública, Rio de Janeiro, v.18, n.6, p.1713-1724, 2002.

TAMBELLINI, A. T.; SCHÜTZ, G. E. Contribuição para o debate do Cebes sobre a Determinação Social da Saúde: repensando processos sociais, determinações e determinantes da saúde. Saúde em Debate, Rio de Janeiro, v.33, n.83, p.371-379, 2009.

FUNDO DAS NAÇÕES UNIDAS PARA A INFÂNCIA - UNICEF. Campanha Nacional pelo Direito à Educação. Brasília, 2013.

UNIVERSIDADE FEDERAL DA PARAÍBA - UFPB. Roteiro para realizar a Cartografia. Especialização em Gestão do Cuidado. João Pessoa: Editora da Universidade Federal da Paraíba, 2011. 